\title{
LA EXIGIBILIDAD DE LOS DERECHOS ECONÓMICOS Y SOCIALES EN EL ÁMBITO INTERAMERICANO Y SU REALIDAD EN URUGUAY
}

María Paula Garat*

\begin{abstract}
RESUMEN. El trabajo estudia la problemática de la exigibilidad de los derechos económicos y sociales a nivel interamericano, para luego contrastarlo con la realidad de Uruguay. Se analizan especialmente los últimos fallos correspondientes a los casos Suárez Peralta (2013) y Gonzales Lluy (2015), ambos respecto de Ecuador. Se observa cómo las dudas y contraposiciones expuestas y/o derivadas de la jurisprudencia de la Corte Interamericana de Derechos Humanos se presentan igualmente en el ámbito jurídico uruguayo. A estos efectos, se consideran algunos casos recientes y de relevancia práctica, los que constituyen ejemplos de la dicotomía asociada a esta materia. Se relacionan, asimismo, los derechos económicos y sociales con la tutela jurisdiccional y con la garantía del plazo razonable, determinando una importante interconexión de necesaria trascendencia en esta temática.
\end{abstract}

PALABRAS CLAVE. Derechos sociales. Eficacia. Tutela judicial. Costos. Plazo razonable.

ABSTRACT. The paper studies the issue of enforceability of economic and social rights at the Inter-American level, in order to draw a contrast with the reality of Uruguay. The decisions on cases Suarez Peralta (2013) and Gonzales Lluy (2015), both with respect to Ecuador, are analyzed. Moreover, the paper observes how doubts and conflicts exposed and/or derived from the Inter-American Court of Human Rights case-law are also presented in the legal field of Uruguay. For this purposes, the author considers some recent cases with practical relevance in Uruguay, which constitute examples of the dichotomy associated with this matter.

* Abogada, Máster en Derecho Constitucional por la Universidad de Sevilla, España, y Postgraduada en Especialización Tributaria por la Universidad Católica del Uruguay. Profesora Ayudante de Derecho Constitucional en la Universidad Católica del Uruguay. Actualmente doctoranda en la Universidad de Sevilla, España. Correo electrónico: paulagarat@hotmail.com 
Economic and social rights are also studied in relation to judicial protection and the guarantee of reasonable judicial timeframe, determining an important interconnection with particular effects in this subject.

KEY WORDS. Social rights. Enforcement. Judicial protection. Costs. Reasonable judicial timeframe.

\section{INTRODUCCIÓN}

El 16 de diciembre del año 2016 se cumplieron cincuenta años trascurridos desde la adopción, por parte de la Asamblea General de Naciones Unidas, del Pacto Internacional de Derechos Económicos, Sociales y Culturales ${ }^{1}$. El 3 de enero de 2016 se cumplieron ya cuarenta años desde su entrada en vigor ${ }^{2}$.

Si bien en estos cincuenta años ha habido grandes avances, la temática de la exigibilidad de los derechos económicos y sociales aún continúa en plena vigencia y cuestionamiento.

Son varios los textos doctrinales, normativos y jurisprudenciales que afirman la interdependencia de los derechos, eliminando cualquier tipo de diferenciación entre los de una y otra generación ${ }^{3}$. No obstante, las dudas sobre la exigibilidad de los derechos económicos y sociales aún continúan, lo que se manifiesta en el ámbito práctico.

La exigibilidad de un derecho y, mayor aún, de un derecho económico o social conllevará un efecto económico, lo que podrá ser más o menos importante. El resultado financiero que una determina decisión posee subyace las consideraciones de cualquier juez o aplicador con competencia para fallar en determinado asunto, ordenando al Estado o entidad pública la realización de cierta actividad.

Esta es, entonces, una de las causas que conllevan a detener determinadas decisiones, auto-restringiendo la actividad del juzgador y evitando, así entonces, una exigibilidad mucho más proclamada.

La decisión que tiende a garantizar un derecho civil o político no respetado por el Estado no parece preocuparnos. No obstante, por el contrario, las sentencias que ordenan la satisfacción de un derecho económico o social son profundamente analizadas, habiendo quienes incluso niegan la posibilidad de tomar decisiones que ocasionen un impacto en la esfera presupuestal. La igualdad-y su más específico postulado de igualdad ante las cargas públicas- pareciera desvanecerse ante tales doctrinas.

1 Resolución de la Asamblea General de Naciones Unidas número 2200 A (XXI), de 16 de diciembre de 1966.

2 El Pacto Internacional de Derechos Económicos, Sociales y Culturales entró en vigor el 3 de enero de 1976, de conformidad con su artículo 27.

3 Tanto la Corte Interamericana de Derechos Humanos, como el Tribunal Europeo de Derechos Humanos se han pronunciado respecto a la interdependencia y exigibilidad de los derechos civiles y políticos, y los económicos, sociales y culturales. Al respecto, cabe citar: Corte IDH. Caso Acevedo Buendía y otros ("Cesantes y Jubilados de la Contraloría”) Vs. Perú, párr. 102 y 103, y Caso Suárez Peralta Vs. Ecuador, párr. 131; y TEDH. Caso Airey Vs. Ireland, párr. 25; y Caso Sidabras and Dziautas Vs. Lituania, párr. 47. 
El afirmar que la protección de los derechos, sean estos civiles y políticos, o económicos y sociales, conlleva costos, no es algo novedoso ${ }^{4}$. No obstante, es en esta última categoría de derechos en los que el aspecto económico se constituye como uno de los puntos de abordaje más extenso, teniendo consecuencias directas en las garantías que se poseen y en su exigibilidad práctica.

Me propongo abordar aquí la temática de la exigibilidad de los derechos económicos y sociales. Partiré, en el primer capítulo, de la perspectiva del Sistema Interamericano de protección de los derechos humanos, analizando particularmente dos de las últimas sentencias emitidas por la Corte Interamericana de Derechos Humanos (Corte IDH). Luego, en segundo lugar, compararé dichos postulados con la realidad jurídica uruguaya. Se observará que los cuestionamientos y dicotomías que es posible hallar en el ámbito interamericano se replican a nivel interno, por lo que un análisis conjunto deviene de necesidad.

Asimismo, y en el tercer capítulo, procuraré vincular la exigibilidad de los derechos económicos y sociales con la noción de tutela jurisdiccional efectiva y con la garantía del plazo razonable, analizando una conexión de indudable trascendencia práctica en esta materia.

Culminaré, finalmente, con algunas reflexiones en torno a esta problemática y a los cincuenta años transcurridos.

\section{LOS DERECHOS ECONÓMICOS Y SOCIALES EN EL ÁMBITO INTERAMERICANO. LOS RECIENTES CASOS SUÁREZ PERALTA Y GONZALES LLUY}

La Convención Americana sobre Derecho Humanos (CADH) refiere a los derechos económicos y sociales en su artículo 26, inserto en el Capítulo III ("Derechos Económicos, Sociales y Culturales"), el que integra la Parte I "Deberes de los Estados y Derechos Protegidos".

El artículo 26, denominado como "Desarrollo Progresivo" establece que:

"Los Estados Partes se comprometen a adoptar providencias, tanto a nivel interno como mediante la cooperación internacional, especialmente económica y técnica, para lograr progresivamente la plena efectividad de los derechos que se derivan de las normas económicas, sociales y sobre educación, ciencia y cultura, contenidas en la Carta de la Organización de los Estados Americanos, reformada por el Protocolo de Buenos Aires, en la medida de los recursos disponibles, por vía legislativa u otros medios apropiados".

Asimismo, el Protocolo Adicional a esta Convención, conocido como "Protocolo de San Salvador", posee por objeto específico el reconocimiento y regulación de los derechos económicos, sociales y culturales, tomando como finalidad la "gran importancia que éstos sean reafirmados, desarrollados, perfeccionados" . Este último documento incluye, entre otros, a los derechos al trabajo, seguridad social, salud y educación.

4 v. HOLMES, Stephen y SUNSTEIN, Cass R; El Costo de los Derechos, Siglo veintiuno editores SA, Buenos Aires, 2011.

5 Esta referencia es realizada en el Preámbulo del Protocolo Adicional a la Convención Americana sobre Derechos Humanos en materia de Derechos Económicos, Sociales y Culturales "Protocolo de San Salvador". 
No obstante lo anterior, es necesario realizar una precisión. Pues, el artículo 19 del Protocolo de San Salvador ${ }^{6}$ establece que el incumplimiento de ciertos aspectos de los derechos sindicales y del derecho a la educación son los susceptibles de ser juzgados ante la Corte IDH.

Por lo tanto, y a pesar del reconocimiento de los derechos económicos y sociales que poseen estos instrumentos, una primera lectura del artículo 19, en su numeral sexto, nos haría afirmar la conclusión de que la exigibilidad de estos derechos, en lo que atañe a la jurisdicción contenciosa de la Corte IDH, se encuentra limitada únicamente para el derecho a la educación y ciertos aspectos de los derechos sindicales.

Cabe entonces preguntarnos si el enunciado antes realizado es correcto. Esto es, si los derechos económicos y sociales - con la exclusión efectuada-no poseen justiciabilidad directa ante la Corte IDH.

Este cuestionamiento fue realizado por la propia jurisprudencia de la Corte IDH en varios de sus pronunciamientos y, con mayor énfasis, en dos de los más recientes fallos: Suárez Peralta Vs. Ecuador (2013) y Gonzáles Lluy Vs. Ecuador (2015).

El caso Suárez Peralta refiere, entre otros puntos, a la vulneración del Estado de Ecuador respecto del derecho a la integridad personal (artículo 5 de la CADH), en tanto la víctima (Melba Suárez Peralta) no recibió una adecuada atención en su salud, lo que le ocasionó diversas y profundas consecuencias ${ }^{7}$.

Por su parte, en el caso Gonzáles Lluy la vulneración de los derechos de la víctima refieren al contagio del virus de la inmunodeficiencia humana (VIH) recibido en una transfusión sanguínea, efectuada cuando tenía tres años de edad, y a las posteriores consecuencias sufridas a causa de ello. La sangre trasfundida era proveniente de un Banco de Sangre de la Cruz Roja y la intervención se concluyó en un centro de salud privado.

Este último constituye el primer caso en el que la Corte IDH declaró la vulneración del derecho a la educación (artículo 13 del Protocolo de San Salvador). Se juzgó, asimismo, la violación de los derechos a la vida (artículo 4 de la CADH) y a la integridad personal (artículo 5 de la $\mathrm{CADH})^{8}$.

¿Por qué no se analizan -y en su caso se condena- respecto del derecho a la salud?

Esta interrogante es la efectuada en ambos fallos, habiendo posiciones contrapuestas dentro de la Corte IDH, expuestas incluso en varios votos concurrentes.

A los efectos de estudiar la exigibilidad de los derechos económicos y sociales a nivel interamericano, habremos de diferenciar, entonces: (a) la posición de la Corte IDH respecto de la exigibilidad de estos derechos y su protección; (b) el contenido y alcance del artículo 26 de la CADH y su vinculación con los artículos 1 y 2 de la CADH; y (c) la posibilidad de

6 Este artículo, en su numeral 6, establece: "En el caso de que los derechos establecidos en el párrafo a) del artículo 8 y en el artículo 13 fuesen violados por una acción imputable directamente a un Estado parte del presente Protocolo, tal situación podría dar lugar, mediante la participación de la Comisión Interamericana de Derechos Humanos, y cuando proceda de la Corte Interamericana de Derechos Humanos, a la aplicación del sistema de peticiones individuales regulado por los artículos 44 a 51 y 61 a 69 de la Convención Americana sobre Derechos Humanos".

7 Corte IDH. Caso Suárez Peralta Vs. Ecuador, párr. 38 y ss.

8 Corte IDH. Caso Gonzales Lluy y otros Vs. Ecuador, párr. 64 y ss. 
proclamar una exigibilidad directa, anunciada pero no concluida, observando una dicotomía en esta materia.

\section{(a) La posición de la Corte IDH respecto de la exigibilidad de los derechos económicos y sociales, y su protección}

La Corte IDH no ha demorado en afirmar la interdependencia e interconexión existente entre los derechos civiles y políticos, respecto de los económicos sociales y culturales. Así entonces, en el Caso Acevedo Buendía Vs. Perú ${ }^{9}$ se cita expresamente el fallo Airey Vs. Irlanda del Tribunal Europeo de Derechos Humanos ${ }^{10}$ que dispone:

"Si bien el Convenio recoge derechos esencialmente civiles y políticos, gran parte de ellos tienen implicaciones de naturaleza económica y social. Por eso, el Tribunal estima, como lo hace la Comisión, que el hecho de que una interpretación del Convenio pueda extenderse a la esfera de los derechos sociales y económicos no es factor decisivo en contra de dicha interpretación, ya que no existe una separación tajante entre esa esfera y el campo cubierto por el Convenio”.

Recientemente, en el caso Gonzales Lluy Vs. Ecuador ${ }^{11}$, la Corte IDH enfatiza la interrelación existente estableciendo que:

"La Corte también considera pertinente recordar la interdependencia e indivisibilidad existente entre los derechos civiles y politicos y los económicos sociales y culturales, ya que deben ser entendidos integralmente como derechos humanos, sin jerarquía entre sí y exigibles en todos los casos ante aquellas autoridades que resulten competentes para ello".

Sin embargo, es únicamente el derecho a la educación el que ha sido tratado en forma autónoma (Caso Gonzales Lluy). A ello precedió una interpretación literal del artículo 19 del Protocolo de San Salvador, que habilita en forma expresa a la Corte IDH a juzgar este derecho ${ }^{12}$.

Los demás derechos, por el contario, no fueron objeto de una justiciabilidad directa. Ello fue calificado como necesario por algunos de los entonces miembros del Tribunal Interamericano, -en aplicación del artículo 19 del Protocolo de San Salvador-, tal lo hizo reiteradamente PÉREZ PÉREZ13 . Otros, sin embargo, reafirmaron que el Tribunal debiera “dar pasos más decididos hacia la justiciabilidad directa"14 de estos derechos.

La Corte IDH no dejó a los derechos económicos y sociales sin exigibilidad o juzgamiento. Por el contrario, y tal ha ocurrido con el derecho a la salud, a pesar de no tratarlo en forma

9 Corte IDH. Caso Acevedo Buendía y otros (“Cesantes y Jubilados de la Contraloría”) Vs. Perú, párr. 101

10 TEDH. Caso Airey Vs. Ireland, párr. 25.

11 Corte IDH. Caso Gonzales Lluy Vs. Ecuador, párr. 172 y Caso Suárez Peralta Vs. Ecuador, párr. 131.

12 Corte IDH. Caso Gonzales Lluy Vs. Ecuador, párr. 234.

13 Véase: Voto Concurrente del Juez Alberto PÉREZ PÉREZ a la Sentencia de la Corte IDH en el Caso Gonzales Lluy Vs. Ecuador; y en el Caso Suárez Peralta Vs. Ecuador.

14 FERRER MAC-GREGOR, Eduardo. Voto Concurrente a la Sentencia de la Corte IDH en el Caso Gonzales Lluy Vs. Ecuador, párr. 23. También cabe observar en el mismo sentido el Voto Concurrente de este Magistrado en el Caso Suárez Peralta Vs. Ecuador, y el Voto Concurrente de la Jueza Margarette MAY MACAULAY en el Caso Furlan y Familiares Vs. Argentina. 
autónoma, incluye su acepción dentro de los derechos a la vida o a la integridad personal, por lo que se logra igualmente esta protección.

En el caso Instituto de Reeducación del Menor Vs. Paraguay la Corte IDH vinculó al derecho a la salud con el concepto de vida digna. Sostuvo que: "un Estado tiene, respecto de niños privados de libertad y, por lo tato, bajo su custodia, la obligación de, inter alia, proveerlos de asistencia de salud y educación"15.

Asimismo, también es posible encontrar estas proposiciones en otros casos sobre vulneración de derechos en centros de reclusión ${ }^{16}$, así como, por otra parte, en lo que atañe a la protección de los derechos de miembros de comunidades indígenas ${ }^{17}$.

En otro orden, el derecho a la salud fue tratado en la jurisprudencia de la Corte IDH en distintos contextos, tales los Casos Ximenes Lopez Vs. Brasilis ; Albán Cornejo Vs. Ecuador $^{19}$; Furlan Vs. Argentina ${ }^{20}$, Suárez Peralta Vs. Ecuador ${ }^{21}$, y Gonzales Lluy Vs. Ecuador. En estos, el contenido del derecho se analiza en los fundamentos de vulneraciones al derecho a la vida o a la integridad física, creando un estándar de protección que, si bien no tratado directamente y con tal nombre, se encuentra, indudablemente, presente en estos fallos ${ }^{22}$.

\section{(b) Contenido y alcance del artículo 26 de la CADH, y su vinculación con los artículos 1 y 2 de la CADH.}

No obstante lograr la tutela y avanzar en los estándares aplicables a estos derechos, corresponde analizar el artículo 26 de la $\mathrm{CADH}$, su vinculación con los artículos 1 y 2 , y la posibilidad de alcanzar una justiciabilidad directa, lo que eliminaría algunas de las cuantiosas y constantes dudas respecto de esta temática.

Conforme sostiene COURTIS ${ }^{23}$, en la interpretación del artículo 26 de la CADH se plantea una primera interrogante, esto es, ¿cuáles son los derechos que se contienen en dicha disposición? Pues, a diferencia de lo que ocurre con los anteriores artículos de la CADH

15 Corte IDH. Caso "Instituto de Reeducación del Menor" Vs. Paraguay, párr. 161

16 Corte IDH. Caso del Penal Miguel Castro Castro Vs. Perú; Caso Vélez Loor Vs. Panamá. Excepciones Preliminares, Fondo, Reparaciones y Costas; Caso Vera Vera y otra Vs. Ecuador; Caso Díaz Peña Vs. Venezuela.

17 Corte IDH. Caso Comunidad Indigena Yakye Axa Vs. Paraguay; Caso Comunidad Indígena Xákmok Kásek. Vs. Paraguay.

18 Corte IDH. Caso Ximenes Lopes Vs. Brasil.

19 Corte IDH. Caso Albán Cornejo y otros. Vs. Ecuador.

${ }^{20}$ Corte IDH. Caso Furlan y Familiares Vs. Argentina.

21 Corte IDH. Caso Suárez Peralta Vs. Ecuador.

22 Respecto al contenido y estándares del derecho a la salud dado en la jurisprudencia de la Corte IDH véase: GARAT, María Paula; "El tratamiento del derecho a la salud en la jurisprudencia de la CIDH", en: Revista de Derecho UCUDAL, 11/2015, pp. 59-79.

En el Caso Alban Cornejo Vs. Ecuador, la Corte IDH sostuvo que: Sostuvo la Corte IDH que: “...el derecho a la vida es un derecho humano fundamental cuyo goce pleno constituye una condición para el ejercicio de todos los derechos. La integridad personal es esencial para el disfrute de la vida humana. A su vez, los derechos a la vida y a la integridad personal se hallan directa e inmediatamente vinculados con la atención de la salud humana”. (Corte IDH. Caso Albán Cornejo y otros. Vs. Ecuador, párr. 117).

23 COURTIS, Christian; "Derechos económicos, sociales y culturales. Artículo 26. Desarrollo Progresivo", en: STEINER, Christian y URIBE, Patricia (Coord.). Convención Americana sobre Derechos Humanos. Comentario, Konrad Adenauer Stiftung, 2014, p. 665. 
la norma no define a los derechos, sino que se remite, para ellos, a otros instrumentos internacionales de protección: las normas económicas, sociales y sobre educación, ciencia y cultura, contenidas en la Carta de la Organización de los Estados Americanos (en adelante "Carta de la OEA"), reformada por el Protocolo de Buenos Aires.

Cabe observar, igualmente, que el intérprete no buscará el derecho en la Carta de la OEA, sino la norma económica, social y sobre educación, ciencia y cultura de la que emane un derecho. Al decir de COURTIS:

"La distinción es importante, porque el texto del articulo 26 sugiere que existen normas en la Carta de la OEA reformada por el Protocolo de Buenos Aires que, sin consagrar directamente derechos, pueden constituir la fuente de derechos en la medida en que éstos se deriven de aquéllas. Como veremos esta doble operación es necesaria en la gran mayoría de los casos, dado que el objeto fundamental de la Carta de la OEA no era el de consagrar directamente derechos para las personas, sino el de crear la organización y fijar sus fines, imponiendo obligaciones a los Estados. En este sentido puede decirse que, pese a lo escueto de su texto, es el artículo 26 de la Convención Americana el que asigna carácter de derechos humanos de las referencias normativas de la Carta de la OEA en la materia-redactadas en términos de principios, objetivos y medidas de política pública que los Estados miembros de la organización se comprometen a adoptar"24.

En adición, es considerar que, en virtud de los postulados emitidos por la Corte IDH en la Opinión Consultiva No. 10/8925 , corresponde acudir a la Declaración Americana de los Derechos y Deberes del Hombre para determinar cuáles son los derechos humanos incluidos en la Carta de la OEA. Asimismo, por aplicación de una interpretación pro hómine o pro persona, -la cual debe ser preferida en normas de derechos fundamentales, y es especialmente contemplada en el artículo 29 de la CADH-, corresponde orientar la interpretación del artículo 26 con otros instrumentos regionales e internacionales de protección, tal el propio Protocolo de San Salvador, además de otros Tratados y Convenciones ${ }^{26}$.

El artículo 26 contiene, por lo tanto, los derechos económicos y sociales o, al menos, la gran mayoría de éstos ${ }^{27}$. Esta inclusión hace a la exigibilidad y justiciabilidad de los mismos ${ }^{28}$, conclusión que se reafirma con una interpretación contextual, que incluya los artículos 1 y 2 de la CADH. Estos últimos establecen la obligación de los Estados de respetar y garantizar los derechos reconocidos, sin discriminación, así como de adoptar las medidas internas, legislativas o de otro carácter, que fueran necesarias para hacer efectivos tales derechos y libertades.

En este punto sostuvo Sergio GARCÍARAMÍREZ que el artículo 26 contempla derechos y que: “. . .los derechos (.. . contenidos en el Pacto San José de Costa Rica y aceptados por

24 Idem.

25 Corte IDH. Opinión Consultiva OC-10/89, párr. 43 y 45

26 Esta interpretación también es sugerida por FERRER MAC-GREGOR en su voto emitido en el Caso Suárez Peralta Vs. Ecuador y en el Caso Gonzáles LLuy Vs. Ecuador.

27 Respecto de la inclusión del derecho a la salud véase: GARAT, María Paula;"El tratamiento del derecho a la salud en la jurisprudencia de la CIDH", Ob. Cit.

28 No me detendré en el análisis de las nociones de "progresividad" y "recursos disponibles", remitiéndome a: GARAT, María Paula; "El tratamiento del derecho a la salud en la jurisprudencia de la CIDH", Ob. Cit. 
los Estados (...) se hallan sujetos al régimen general de supervisión y decisión, o dicho de otra manera, a los "medios de protección"29.

\section{(c) La posibilidad de proclamar una exigibilidad directa, anunciada pero no concluida, observando una dicotomía en esta materia.}

Los derechos económicos y sociales, por consiguiente, pueden ser objeto de una justiciabilidad directa, en aplicación del artículo 26 de la CADH, en su conexión con los artículos 1 y 2 , todos ellos sujetos a la competencia de la Corte IDH.

Si bien la Corte IDH ha efectuado un importante avance en relación con la tutela de algunos derechos económicos y sociales, otorgándoles un contenido preciso y desarrollando estándares en su delimitación; constituye un contrasentido no poder hacerlo en forma directa.

En los casos Suárez Peralta o Gonzales Lluy, entre otros, la Corte IDH podría haber juzgado el cumplimiento del artículo 26 de la CADH. En este sentido se pronunció el Juez FERRER MAC-GREGOR:

"Desde mi perspectiva, se requiere un desarrollo del Artículo 26 del Pacto de San José en la jurisprudencia de la Corte IDH que podría representar nuevos derroteros para la efectividad de los derechos económicos, sociales y culturales, tanto en sus dimensiones individual y colectiva. Y podría configurarse un nuevo contenido en el futuro a través de interpretaciones evolutivas que refuercen el carácter interdependiente e indivisible de los derechos humanos" $"$.

La dicotomía imperante en esta materia, por tanto, se observa fácilmente. Por una parte, la Corte IDH afirmó la interdependencia e interconexión entre los derechos civiles y políticos; y los económicos y sociales. Asimismo, ciertos derechos económicos y sociales fueron tratados -aunque en forma indirecta - originando trascendentes estándares y obligaciones a ser cumplidas por los Estados. No obstante y, por otra parte, se continúa concluyendo en la imposibilidad de juzgarlos en forma autónoma; se duda apenas de nombrar al derecho económico o social tratado ${ }^{31}$.

La posición dada al juzgador interno es confusa en un doble sentido. Pues, la exigibilidad directa parece cuestionada, punto que podría encontrar conexión con alguna norma de derecho interno, quizás, con redacción similar al artículo 26 de la CADH, o bien que hace a la percepción general de esta temática. En adición, el contenido de ciertos derechos-como la vida o la integridad personal- parecieran ampliarse de forma tal que podría conllevar, al aplicador, a una grave duda respecto del alcance y delimitación de cada uno de los derechos implicados en un caso concreto. Esto tendría consecuencias no solo al momento de juzgar

29 GARCÍA RAMÍREZ, Sergio; "Protección jurisdiccional internacional de los derechos económicos, sociales y culturales", en: Revista Cuestiones Constitucionales, 9/2003.

30 FERRER MAC-GREGOR, Eduardo. Voto Concurrente en el Caso Gonzáles LLuy Vs. Ecuador, párr. 36 .

${ }^{31}$ Véase en este punto el Voto Concurrente del Juez PÉREZ PÉREZ en el Caso Suárez Peralta Vs. Ecuador en el que se expone: "La finalidad del presente voto razonado es exclusivamente dejar en claro que las referencias al derecho a la salud contenidas en la sentencia no significan que se esté asumiendo competencia en relación con ese derecho en particular, o con los derechos económicos, sociales y culturales en general". 
la aplicación de dichos derechos sino, asimismo, al analizar las restricciones en atención al principio de proporcionalidad ${ }^{32}$.

\section{III.LA PROBLEMÁTICA ASOCIADA EN URUGUAY. \\ LA EXIGIBILIDAD DEL DERECHO A LA SALUD Y OTROS DERECHOS ECONÓMICOS Y SOCIALES}

En Uruguay, es posible observar el contrapunto antes descripto. El caso de la solicitud de medicamentos de alto costo ante el Poder Judicial es ejemplo de ello.

El artículo 44 de la Constitución de Uruguay establece que:

"El Estado legislará en todas las cuestiones relacionadas con la salud e higiene públicas, procurando el perfeccionamiento físico, moral y social de todos los habitantes del país.

Todos los habitantes tienen el deber de cuidar su salud, así como el de asistirse en caso de enfermedad. El Estado proporcionará gratuitamente los medios de prevención y de asistencia tan sólo a los indigentes o carentes de recursos suficientes".

Con fundamento en el mismo, diversos enfermos oncológicos o de afecciones graves han solicitado, en acción de amparo ante el Poder Judicial, que se exigiere al Estado la provisión de los medicamentos recetados, de imposible acceso económico para su situación financiera, y que brindarían un mejoramiento o, al menos, alargamiento de su proyección de vida.

Cabe aclarar que las normas jurídicas legales e infralegales uruguayas dan creación a un sistema por el cual el Fondo Nacional de Recursos-entidad paraestatal- brinda ciertos fármacos, los que son definidos según el Formulario Terapéutico de Medicamentos, cuerpo que el Ministerio de Salud Pública está obligado a sancionar y actualizar ${ }^{33}$.

Las primeras sentencias dictadas en esta temática fueron en su mayoría desestimatorias, con una preocupación por la separación de poderes, por la igualdad y por el coste económico de la decisión ${ }^{34}$. En este sentido, el Tribunal de Apelaciones en lo Civil de Quinto Turno expuso que:

“. . ha de considerarse que no parece ajustado a Derecho que por la vía excepcional y sumaria del amparo, el Poder Judicial se sustituya a la Administración en el ejercicio de funciones para las cuales es legítimamente competente, invadiendo áreas de política de salud, técnico-médicas y asistenciales, con opciones de conveniencia y utilidad propias del gobierno de la salud...”35.

${ }^{32}$ Me refiero especialmente al momento de realizar el análisis preliminar y conceptualizar cada uno de los derechos involucrados. Al respecto véase: GARAT, María Paula; El principio de proporcionalidad y su contrastación empírica, UCUDAL, Montevideo, 2015, pp. 28 y ss.

33 El cuerpo normativo infraconstitucional en esta materia está conformado por las siguientes normas de Uruguay: el artículo 264 de la Ley $\mathrm{N}^{\circ} 17.930$, la Ley $\mathrm{N}^{\circ} 18.335$, Decreto del Poder Ejecutivo $\mathrm{N}^{\circ} 265 /$ 006 y Ordenanza Ministerial No. 775.

${ }^{34}$ Por ejemplo, véase: Sentencia del Tribunal de Apelaciones en lo Civil de Quinto Turno de Uruguay, Número 107/2009, y Sentencia del Tribunal de Apelaciones en lo Civil de Sexto Turno de Uruguay, Número 209/2009.

35 Sentencia del Tribunal de Apelaciones en lo Civil de Quinto Turno de Uruguay, Número 101/2007. 
En otros fallos se hizo referencia a las normas sobre salud, referenciadas en el Pacto Internacional de Derechos Económicos, Sociales y Culturales, así como en la Declaración Americana sobre los Derechos y Deberes del Hombre, dejando de lado el precepto contenido en la Constitución -el que correspondería aplicar según la directriz de preferencia de normas (artículo 29 de la CADH)-, argumentando que por las mismas el Estado es obligado a "la adopción de políticas "hasta el máximo de los recursos" de que disponga (...) y los avances de la técnica en términos de "gradualidad", en forma progresiva"36. En su mérito, el Poder Judicial no podría sustituir a la Administración en el ejercicio de funciones para las cuales es ésta última la competente, "invadiendo áreas de política de salud"ß̧7.

No obstante, en otras decisiones, el análisis conllevó a una aplicación directa del artículo 44 de la Constitución, lo que actualmente se reitera con mayor asiduidad. El cuestionamiento respecto de la separación de poderes y del aspecto económico ha disminuido en forma considerable.

En el fallo dictado por el Tribunal de Apelaciones en lo Civil de Séptimo Turno se sostuvo que:

"La protección efectiva del derecho a la vida o a la salud de las personas no puede depender, en el Estado de Derecho Constitucional y Social, de su capacidad económica o situación de privilegio que le posibilite afrontar sin esfuerzo el costo del tratamiento médico indicado para la curación de su enfermedad o la sobrevida en condiciones que contemplen la dignidad inherente a su ser existencial.

El Poder Judicial no pretende inmiscuirse a través del instituto del Amparo en las esferas de competencias de organismos estatales o paraestatales. En este asunto se atiende otras cuestiones y bienes (...) La solución que se propicia no implica violación al principio de separación de poderes ni pretende sustraer competencias a otros organismos. En el caso no se plantea decidir sobre politicas de salud (donde ciertamente el Poder Judicial carece de competencia), sino proteger derechos de rango constitucional que están siendo conculcados y de constatarse la violación, ordenar a la Administración para que los observe. Ello por cuanto no puede discutirse que el derecho fundamental a la protección de la salud de las personas debe llevarlo a cabo el Estado a través de todos los medios disponibles y en beneficio de todas las personas" ${ }^{38}$.

Sin embargo, dado el efecto de una mayor cantidad de sentencias condenatorias, la problemática tuvo su repercusión en la esfera legislativa. Pues, en el marco de la discusión del Proyecto de Ley de Presupuesto Nacional, para el período 2015 a 2019, se incorporaron normas que limitan en forma expresa las obligaciones y la responsabilidad estatal en esta materia $^{39}$. Advertida la inconstitucionalidad que aparejaría, las discusiones no se hicieron esperar, y el aspecto económico se volvió a confrontar a la clara interpretación del precepto constitucional.

\footnotetext{
36 Sentencia del Tribunal de Apelaciones en lo Civil de Quinto Turno de Uruguay, Número 63/2010. En igual sentido, véase: Sentencia del Tribunal de Apelaciones en lo Civil de Sexto Turno de Uruguay, Número 209/2009.

37 Ídem.

38 Sentencia del Tribunal de Apelaciones en lo Civil de Séptimo Turno, del 11 de febrero de 2016.

39 Me refiero a los artículos 448, 461 y 462 de la Ley $\mathrm{N}^{\circ} 19.355$.
} 
Por su parte, la Suprema Corte de Justicia, mediante las Sentencias 396/2016 y 436/ $2017^{40}$, declaró la inconstitucionalidad del artículo 7 de la Ley $18.335^{41}$, el que también limitaba las obligaciones estatales en esta temática.

La exigibilidad de este derecho, que pareciera desprenderse en forma manifiesta de la norma constitucional, se mantiene, entonces, con avances y retrocesos, tal ocurre con la jurisprudencia interamericana y algunos de sus votos concurrentes.

Esta conclusión también se manifiesta en otros casos y, con mayor énfasis, en las sentencias estructurales. Estas son definidas como las que afrontan causas que, de modo sistemático, producen un desconocimiento generalizado, recurrente y grave de los derechos humanos ${ }^{42}$.

En Uruguay, una sentencia calificada por la doctrina como estructural ${ }^{43}$ refirió al hacinamiento carcelario y fue revocada en segunda instancia, bajo el argumento de no poderse dar solución a estos problemas en la vía jurisdiccional:

“.. el amparo no sería la vía idónea o adecuada para modificar tan lamentable situación.- Y no lo sería, por las mismas razones que impiden que el amparo solucione tantas otras situaciones en las que están en juego derechos humanos, sin que ninguno de los sujetos involucrados -incluido el Estado, pero no sólo éste- adopte las medidas necesarias para revertir la situación: niños en situación de calle, ancianos y psicópatas en establecimientos públicos, personas sin vivienda, sin acceso a las prestaciones de salud. (...) Se encuentra en juego el principio de separación de poderes"44.

Las sentencias estructurales ingresan, entonces, en la problemática antedicha y, máxime, si lo que se trata de garantizar es un derecho económico o social.

\section{LOS DERECHOS ECONÓMICOS Y SOCIALES. LA TUTELA JURISDICCIONAL Y EL PLAZO RAZONABLE.}

Los derechos económicos y sociales se encuentran reconocidos en innumerables normas constitucionales e internacionales. Sin embargo, su efectividad práctica y su ejecución por la vía jurisdiccional ha transitado por varias dificultades.

40 Sentencias de la Suprema Corte de Justicia No. 396/2016 del 5 de octubre de 2016, y 436/2017 del 27 de abril de 2017. Es de destacar que la primera de las nombradas posee discordia de la Ministra Elena MARTÍNEZ, y la segunda posee discordia de la Ministra Elena Martínez y del Ministro Eduardo TURELL.

${ }_{41}$ El inciso 2 del artículo 7 de la Ley 18.335 establece: "Todo paciente tiene el derecho a acceder a medicamentos de calidad, debidamente autorizados por el Ministerio de Salud Pública e incluidos por éste en el formulario terapéutico de medicamentos, y a conocer los posibles efectos colaterales derivados de su utilización".

${ }_{22}$ OSUNA, Néstor: "Las sentencias estructurales. Tres ejemplos de Colombia" en: Justicia Constitucional y Derechos Fundamentales, 5/2015, pp. 91-116.

43 RISSO FERRAND, Martín; "Sentencias estructurales. Comentario preliminar al trabajo de Néstor Osuna titulado "Las sentencias estructurales. Tres ejemplos de Colombia", en Justicia Constitucional y Derechos Fundamentales, 5/2015, pp. 117 y 118. Me refiero a la Sentencia del Juzgado Letrado de Primera Instancia en lo Contencioso Administrativo de Primer Turno de Uruguay, del 8 de junio de 2009.

44 Sentencia del Tribunal de Apelaciones en lo Civil de Tercer Turno de Uruguay, Número 156/2009. 
La tutela jurisdiccional efectiva, por consiguiente, se debilita en esta materia, pues el recurso sencillo, rápido y efectivo que demanda el artículo 25 de la CADH, entre otras normas, no se vislumbra en la realidad de muchos casos.

La sencillez, rapidez y efectividad en el procedimiento constituyen tres características que, necesariamente, se entremezclan en el análisis de la exigibilidad de un derecho y, fundamentalmente, de su tutela.

La garantía del plazo razonable, en este punto, deviene también esencial. Cuando de la protección de un derecho económico o social se trata, el factor tiempo es primordial, siendo ello un significativo punto que hace a su exigibilidad.

La Corte IDH ha utilizado tres parámetros para analizar la razonabililidad en el plazo, garantía estatuida en el artículo 8 de la CADH: (a) la complejidad del asunto, (b) la actividad procesal del interesado, y (c) la conducta de las autoridades judiciales ${ }^{45}$.

A estos tres, fue agregado un cuarto aspecto, primeramente sostenido por el Juez Sergio GARCÍARAMÍREZ ${ }^{46}$, e incorporado por la Corte IDH en el año 2008 a partir del caso Valle Jaramilloy otros Vs. Colombia ${ }^{47}$. Este cuarto elemento refiere a la afectación generada por la duración del procedimiento en la situación jurídica de la persona.

\section{Sostuvo GARCÍA RAMÍREZ que:}

"Me referí, como posible cuarto elemento a considerar para la estimación del plazo razonable, a lo que denominé "afectación actual que el procedimiento implica para los derechos y deberes —es decir, la situación jurídica-del individuo”. Es posible que aquél incida de manera poco relevante sobre esa situación; si no es así, es decir, si la incidencia crece, hasta ser intensa, resultará necesario, en bien de la justicia y la seguridad seriamente comprometidas, que el procedimiento corra con más diligencia a fin de que en breve tiempo - "plazo razonable”- se resuelva la situación del sujeto, que ha comenzado a gravitar severamente sobre la vida de éste. La afectación debe ser actual, no meramente posible o probable, eventual o remota" ${ }^{48}$.

El Tribunal Europeo de Derechos Humanos, en análogo sentido, ha vertido un especial énfasis en el interés en el proceso que posee la persona y la importancia de este para su proyecto de vida.

En el caso El Massry Vs. Austria se expone que del análisis de la complejidad del asunto y de la conducta de los intervinientes no se concluiría en una falta de razonabilidad del tiempo. Sin embargo, considerando el estado de salud de la víctima y la gran importancia que el proceso tenía para ésta, los once años transcurridos no fueron razonables ${ }^{49}$.

45 Corte IDH. Caso Genie Lacayo Vs. Nicaragua.

46 A partir de su voto razonado en el Caso López Álvarez vs. Honduras (2006), el Juez Sergio GARCÍA RAMÍREZ sostuvo la conveniencia de incorporar un cuarto elemento a las consideraciones sobre el plazo razonable. Dicha postura se mantuvo, luego, por el mismo Juez, por ejemplo, en los votos de las Sentencias en: Corte IDH. Caso Comunidad Indigena Sawhoyamaxa Vs Paraguay y Caso de las Masacres de Ituango Vs. Colombia.

47 Corte IDH. Caso Valle Jaramillo y otros Vs. Colombia, párr.155.

48 Voto razonado del Juez Sergio GARCÍA RAMÍREZ en el Caso López Álvarez Vs. Honduras (2006), párr. 36.

49 En este caso se establece que: “As to the authorities' conduct, the Court observes that there were no substantial periods of inactivity. However, considering the applicant's state of health and the great importance of the outcome of the proceedings for him, the Court finds that a period of almost eleven years exceeds a reasonable time”. TEDH. Caso El Massry v. Austria, párr. 44. 
Similares reparos fueron efectuados en el caso Laudon Vs. Alemania, sobre mala praxis médica. En el mismo el TEDH sostuvo que:

"...the Court cannot but conclude that the proceedings at issue were of vital importance to the applicant. She has been unable to work in her previous job since the improper medical treatment she had received when she was only 26 years old. The proceedings, (...) were therefore decisive for the way in which she would make her living for possibly the rest of her working lifetime"

La jurisprudencia de la Corte IDH y del Tribunal Europeo de Derechos Humanos es, entonces, coincidente en este punto, y así ha sido también manifestado en los dos recientes casos comentados ${ }^{51}$.

En el fallo Gonzáles Lluy Vs. Ecuador, la Corte IDH enfatizó que:

“.. para determinar la razonabilidad del plazo se debe tomar en cuenta la afectación generada por la duración del procedimiento en la situación jurídica de la persona involucrada en el mismo, considerando, entre otros elementos, la materia objeto de controversia. En este sentido, este Tribunal ha establecido que si el paso del tiempo incide de manera relevante en la situación jurídica del individuo, resultará necesario que el procedimiento avance con mayor diligencia a fin de que el caso se resuelva en un tiempo breve.

\section{(...)}

Asimismo, el Tribunal Europeo ha conocido casos en los cuales el debate de los procesos en curso se encontraba relacionado con la situación de una persona con VIH. En el caso X Vs. Francia, el Tribunal Europeo analizó el incumplimiento de las garantías judiciales tomando en cuenta que lo que estaba en juego en el proceso judicial era de crucial importancia para el peticionario, debido a la naturaleza de su enfermedad. El Tribunal indicó que en el referido caso era requerida una "diligencia excepcional", independientemente de la cantidad de casos pendientes. Asimismo, en el caso F.E. Vs. Francia, el Tribunal Europeo señaló que esta diligencia excepcional debía operar aun entendiendo cierto nivel de complejidad en este tipo de casos"52

La garantía del plazo razonable, por lo tanto, y además de la complejidad del asunto y de la conducta de los intervinientes, posee otro ingrediente de especial análisis: la consideración de la importancia del procedimiento para la víctima; la afectación de la duración en su situación jurídica.

Es este el elemento que se vincula de forma particular con la exigibilidad de un derecho económico y social, pues la efectividad de este último podría depender del plazo en cuestión.

La pendencia de la eficacia de un derecho económico o social en un proceso es, entonces, de significancia. El procedimiento debiera poseer una mayor celeridad, -y así impulsarse por la autoridad-, cuando se inmiscuye la especial importancia que el mismo posee para la situación del interesado. Esto se relaciona intrínsecamente con la propia exigibilidad de los derechos económicos y sociales y con el logro de una tutela jurisdiccional efectiva para éstos.

\footnotetext{
50 TEDH. Caso Laudon Vs. Germany, párr. 72.

${ }^{51}$ v. Corte IDH. Caso Suárez Peralta Vs. Ecuador, párr. 102 y 103; y Caso Gonzáles Lluy Vs. Ecuador, párr. 309 y ss.

52 Cote IDH. Caso Gonzáles Lluy Vs. Ecuador, párr. 309 y 313.
} 


\section{CONCLUSIONES}

La temática de la exigibilidad de los derechos económicos y sociales no es nueva, sino que ha sido varias veces tratada por la doctrina constitucionalista. No obstante, su significancia y trascendencia para el Derecho Constitucional mantiene vigencia, aún luego de cincuenta años de su reconocimiento expreso.

La problemática inserta en esta materia hace referencia a dos puntos de trascendencia. Por una parte, al efecto económico que la garantía de estos derechos conlleva. En segundo término, a la competencia de los Tribunales jurisdiccionales para ordenar su cumplimiento.

Actualmente, ambos aspectos deben ser reconsiderados.

Las fricciones que pudieren haber entre los Poderes del Estado, así como entre el Estado y una Corte regional o internacional son connaturales al sistema, pues forman parte de la actividad misma de juzgar y ejecutar lo juzgado. La auto-restricción que se sustente en meros aspectos políticos o presupuestales, pero no jurídicos, no debiera poseer razón de ser.

La justiciabilidad de ciertos derechos económicos y sociales puede ser directa en el caso del Sistema Interamericano, correspondiendo aplicar el artículo 26 de la CADH, cuyo desarrollo ha sido hasta ahora escaso. Se demanda, por lo tanto, una mayor precisión de los términos contenidos en el mismo, lo que, sin dudas, sería de gran utilidad y referencia para la esfera interna.

En la jurisprudencia de la Corte IDH es posible observar un gran avance en lo que refiere a la exigibilidad de los derechos económicos y sociales, y a los estándares a ser requeridos a los Estados en su cumplimiento. Sin embargo, las vacilaciones en torno a esta cuestión se hacen notar al tener que mezclar estos derechos dentro del contenido de otros, para hacerlos justiciables. La interdependencia e interconexión existente resulta evidente, pero ello no debe significar una confluencia en la definición de los derechos en cuestión, imposibilitando, en definitiva, una delimitación más precisa de los mismos.

A pesar de los invaluables aportes al cumplimiento normativo, el considerar la vulneración del derecho a la salud necesariamente inserta dentro de la violación a la vida o integridad personal, hace perder a este derecho de contenido y eficacia autónoma.

Asimismo, y además de ciertos estándares aplicables, algunas Constituciones han previsto obligaciones específicas a cargo del Estado, como es el caso del artículo 44 de la Constitución uruguaya. En estos supuestos, la exigibilidad de los derechos económicos y sociales no debiera afrontar dudas.

La dicotomía imperante en esta materia, por lo tanto, se observa en el ámbito interamericano y, en similar media, en la esfera interna de Uruguay. Una reconsideración de este punto es entonces necesaria, máxime a cincuenta años de la adopción del Pacto Internacional de Derechos Económicos, Sociales y Culturales.

Este paralelismo queda claro al observar la jurisprudencia uruguaya sobre amparo de medicamentos, entre otros ejemplos que muestran cómo argumentos presupuestarios y financieros son muchas veces empleados para desestimar la protección de los derechos. El origen de ello es, a mi parecer y entre otros, el cuestionamiento inserto en el propio Sistema Interamericano, aquí analizado. Sus consecuencias, además de repercutir negativamente en la efectividad del derecho, teniendo efectos adversos en los casos estructurales, implican, 
en definitiva, el debilitamiento de la norma constitucional en sí misma, en tanto no se aplica el mandato que establece, siendo ello por demás grave.

En adición a lo anterior, y en relación a estos derechos, la garantía del plazo razonable es de una importancia fundamental. La afectación de la situación del interesado o la importancia que el asunto posee para el mismo y, en esto, la pendencia en la eficacia de un derecho, son de significancia, lo que corresponde sea considerado dentro del parámetro exigido y lo que se relaciona en forma intrínseca con la exigibilidad misma del derecho involucrado.

Tal precisó la Corte IDH: “. . .no basta que los recursos existan formalmente, sino que los mismos deben dar resultados o respuestas a las violaciones de derechos humanos, para que éstos puedan ser considerados efectivos" ${ }^{\text {53 }}$.

Luego de cincuenta años, por tanto, la exigibilidad de los derechos económicos y sociales, lejos de considerarse un asunto acabado, posee diversas vertientes de necesario análisis y profundización, tanto en el ámbito interamericano, como en el interno.

A modo de epílogo, la autora aclara que en forma posterior a la redacción y al envío de este trabajo para su publicación, con fecha 13 de noviembre de $2017^{54}$ se dio a conocer, por parte de la Corte IDH, la Sentencia Lagos del Campo Vs. Perú ${ }^{55}$. En esta, y a diferencia de las anteriores citadas en este estudio, la Corte IDH condenó a Perú por haber vulnerado el artículo 26 de la CADH. Este fallo, histórico por su significancia, debe ser destacado y otorga un nuevo puntapié para que la tutela directa de los derechos económicos, sociales y culturales, en el Sistema Interamericano y, consecuentemente, en los sistemas internos, se haga realmente efectiva.

El desarrollo del artículo 26 de la CADH que antes era escaso, se vio entonces reforzado, esperándose que la temática se reconsidere en el ámbito interamericano y, en especial, en la esfera interna.

\section{BIBLIOGRAFÍA CONSULTADA}

ABRAMOVICH, Víctor y COURTIS, Christian; Los derechos sociales como derechos exigibles, Trotta, España, 2002.

CANÇADO TRINDADE, Antonio A; La protección internacional de los Derechos Económicos, Sociales y Culturales, disponible en: http://www.codehupy.org/redesddhh/wpcontent/uploads/ Proteccion_internaciones_DESC_Cancado_Trindade.pdf Fecha de consulta: 17.09.2017

COURTIS, Christian; "Derechos económicos, sociales y culturales. Artículo 26. Desarrollo Progresivo", en: STEINER, Christian y URIBE, Patricia (Coord.). Convención Americana sobre Derechos Humanos. Comentario, Konrad Adenauer Stiftung, 2014, pp. 654-676.

GARAT, María Paula. El principio de proporcionalidad y su contrastación empírica, UCUDAL, Montevideo, 2015.

${ }^{53}$ Corte IDH. Caso Maritza Urrutia Vs. Guatemala, párr. 117; y Caso Acosta Calderón Vs. Ecuador, párr. 93.

54 A este respecto puede observarse el comunicado emitido por la Corte IDH: http://www.corteidh.or.cr/ docs/comunicados/cp_39_17.pdf Fecha de consulta: 15/3/2018

55 Corte IDH. Caso Lagos del Campo Vs. Perú. Excepciones Preliminares, Fondo, Reparaciones y Costas. Sentencia de 31 de agosto de 2017. Serie C No. 340. La sentencia aborda el derecho a la estabilidad laboral que no se encuentra comprendido en la justiciabilidad expresa del artículo 19 del Protocolo de San Salvador. 
GARAT , María Paula. "El tratamiento del derecho a la salud en la jurisprudencia de la CIDH" en: Revista de Derecho UCUDAL, 11/2015, pp. 59-79.

GARCÍA RAMÍREZ, Sergio; "Protección jurisdiccional internacional de los derechos económicos, sociales y culturales", en: Revista Cuestiones Constitucionales, 9/2003.

HOLMES, Stephen y SUNSTEIN, Cass R; El Costo de los Derechos, Siglo veintiuno editores SA, Buenos Aires, 2011.

OSUNA, Néstor: "Las sentencias estructurales. Tres ejemplos de Colombia" en: Justicia Constitucional y Derechos Fundamentales, 5/2015, pp. 91-116.

PARRA, Oscar; Justiciabilidad de los derechos económicos, sociales y culturales ante el Sistema Interamericano, Comisión Nacional de Derechos Humanos, México, 2011.

RISSO FERRAND, Martín; "Sentencias estructurales. Comentario preliminar al trabajo de Néstor Osuna titulado "Las sentencias estructurales. Tres ejemplos de Colombia", en Justicia Constitucional y Derechos Fundamentales, 5/2015, pp. 117-124.

\section{Jurisprudencia Consultada}

Corte IDH. Interpretación de la Declaración Americana de los Derechos y Deberes del Hombre en el Marco del Artículo 64 de la Convención Americana sobre Derechos Humanos. Opinión Consultiva OC-10/89 del 14 de julio de 1989. Serie A No. 10.

Corte IDH. Caso Genie Lacayo Vs. Nicaragua. Fondo, Reparaciones y Costas. Sentencia del 29 de enero de 1997. Serie C No. 30.

Corte IDH. Caso Maritza Urrutia Vs. Guatemala. Fondo, Reparaciones y Costas. Sentencia de 27 de noviembre de 2003. Serie C No. 103.

Corte IDH. Caso "Instituto de Reeducación del Menor" Vs. Paraguay. Excepciones Preliminares, Fondo, Reparaciones y Costas. Sentencia de 2 de septiembre de 2004. Serie C No. 112.

Corte IDH. Caso Comunidad Indigena Yakye Axa Vs. Paraguay. Fondo Reparaciones y Costas. Sentencia 17 de junio de 2005. Serie C No. 125.

Corte IDH. Caso Acosta Calderón Vs. Ecuador. Fondo, Reparaciones y Costas. Sentencia de 24 de junio de 2005. Serie C No. 129.

Corte IDH. Caso Ximenes Lopes Vs. Brasil. Excepción Preliminar. Sentencia de 30 de noviembre de 2005. Serie C No. 139.

Corte IDH. Caso López Álvarez Vs. Honduras. Fondo, Reparaciones y Costas. Sentencia de 1 de febrero de 2006. Serie C No. 141.

Corte IDH. Caso Comunidad Indígena Sawhoyamaxa Vs Paraguay. Fondo, Reparaciones y Costas. Sentencia de 29 de marzo de 2006. Serie C No. 146

Corte IDH. Caso de las Masacres de Ituango Vs. Colombia. Excepción Preliminar, Fondo, Reparaciones y Costas. Sentencia de 1 de julio de 2006. Serie C No. 148.

Corte IDH. Caso del Penal Miguel Castro Castro Vs. Perú. Fondo, Reparaciones y Costas. Sentencia de 25 de noviembre de 2006. Serie C No. 160.

Corte IDH. Caso Albán Cornejo y otros. Vs. Ecuador. Fondo Reparaciones y Costas. Sentencia de 22 de noviembre de 2007. Serie C No. 117.

Corte IDH. Caso Valle Jaramillo y otros Vs. Colombia. Fondo, Reparaciones y Costas. Sentencia de 27 de noviembre de 2008. Serie C No. 192.

Corte IDH. Caso Acevedo Buendía y otros (“Cesantes y Jubilados de la Contraloría”) Vs. Perú. Excepción Preliminar, Fondo, Reparaciones y Costas. Sentencia de 1 de julio de 2009. Serie C No. 198.

Corte IDH. Caso Comunidad Indígena Xákmok Kásek. Vs. Paraguay. Fondo, Reparaciones y Costas. Sentencia de 24 de agosto de 2010 Serie C No. 214.

Corte IDH. Caso Vélez Loor Vs. Panamá. Excepciones Preliminares, Fondo, Reparaciones y Costas. Sentencia de 23 de noviembre de 2010 Serie C No. 218. 
Corte IDH. Caso Vera Veray otra Vs. Ecuador; Caso DíazPeña Vs. Venezuela. Excepción Preliminar, Fondo, Reparaciones y Costas. Sentencia de 26 de junio de 2012. Serie C No. 244.

Corte IDH. Caso Furlan y Familiares Vs. Argentina. Excepciones Preliminares, Fondo, Reparaciones y Costas. Sentencia de 31 de agosto de 2012. Serie C No. 24

Corte IDH. Caso Suárez Peralta Vs. Ecuador. Excepciones Preliminares, Fondo, Reparaciones y Costas. Sentencia de 21 de mayo de 2013. Serie C No. 261.

Corte IDH. Caso Gonzales Lluy y otros Vs. Ecuador. Excepciones Preliminares, Fondo, Reparaciones y Costas. Sentencia de 1 de septiembre de 2015. Serie C No. 298.

TEDH. Caso Airey Vs. Ireland. Número de Aplicación 6289/73. Sentencia de 9 de octubre de 1979.

TEDH. Caso Sidabras and Dziautas Vs. Lituania. Número de Aplicación 55480/00, 55480/00, y 59330/00, Sentencia de 27 de Julio de 2004.

TEDH. Caso El Massry v. Austria. Application no. 61930/00, del 22 marzo de 2005.

TEDH. Caso Laudon v. Germany. Application no. 14635/03, Sentencia del 26 de abril de 2007. Juzgado Letrado de Primera Instancia en lo Contencioso Administrativo de Primer Turno de Uruguay, del 8 de junio de 2009.

Tribunal de Apelaciones en lo Civil de Tercer Turno de Uruguay, Número 156/2009, del 20 de julio de 2009.

Tribunal de Apelaciones en lo Civil de Quinto Turno de Uruguay, Número 101/2007, dictada el 17 de agosto de 2007.

Tribunal de Apelaciones en lo Civil de Sexto Turno de Uruguay, Número 209/2009, del 19 de agosto de 2009.

Tribunal de Apelaciones en lo Civil de Quinto Turno de Uruguay, Número 107/2009, del 18 de setiembre de 2009.

Tribunal de Apelaciones en lo Civil de Quinto Turno de Uruguay, Número 63/2010, del 28 de mayo de 2010.

Tribunal de Apelaciones en lo Civil de Séptimo Turno, del 11 de febrero de 2016.

Suprema Corte de Justicia, Número 396/2016, del 6 de octubre de 2016.

Suprema Corte de Justicia, Número 436/2017, del 26 de abril de 2017.

Fecha de recepción: 2 febrero 2018.

Fecha de aceptación: 13 de marzo 2018. 
